\title{
Management dilemma in papillary carcinoma arising from struma ovarii
}



\author{
Ana Hreniuc ${ }^{1}$, Simona Gherasim¹, Cristina Preda ${ }^{1}$, Carmen Vulpoi ${ }^{1}$, Maria-Christina \\ Ungureanu ${ }^{1}$, Voichita Mogos $^{1}$, Doina Piciu ${ }^{3}$, Radu Danila² ${ }^{2}$ Letitia Leustean $^{1}$ \\ 1-Department of Endocrinology-University of Medicine and Pharmacy "Gr.T. Popa" Iasi, Romania \\ 2-Surgery Department- St. Spiridon Hospital lasi, University of Medicine and Pharmacy "Gr.T.Popa" Iasi, Romania \\ 3-Oncological Institute-"Prof.Dr.Ion.Chiricuta"-Cluj-Napoca, Romania
}

\section{Introduction}

- A rare ovarian teratoma consisting mainly of thyroid tissue, struma ovarii accounts for up to $3 \%$ of all ovarian tumors. The thyroid tissue may demonstrate the same spectrum of pathological features as in the normal thyroid including benign and malignant changes. The majority of cases are diagnosed post-operatively.

- The age of presentation of malignancy in struma ovarii is usually in the 5th decade of life. Patients are usually asymptomatic or predominantly presented with a pelvic mass in $45 \%$ of cases or abdominal pain. Menstrual irregularities and clinical hyperthyroidism have been noted.

- The most common type is PTC, followed by FTC and the recent form of highly differentiated follicular carcinoma (HDFCO), characterized by extra ovarian dissemination of thyroid elements.

\section{Case Report}

- We present the case of a patient known with morbid obesity, candidate for gastric sleeve surgery, had been followed up for about one year for a right ovarian cyst of $44 / 34 \mathrm{~mm}$ revealed at the preoperative echography. Complementary pelvic MRI examination showed an increased cyst volume-79/66/72 mm. Suspecting a neoplasia because of the slightly elevated of CA 125- 85 U/ml (0-35 $\mathrm{U} / \mathrm{ml}$ ), she underwent exploratory laparotomy and total abdominal hysterectomy with bilateral salphingo-oophorectomy.

Histopathology exam= Struma ovarii which consisted of benign thyroid follicles with colloid and hyperplastic areas and predominantly malignant papillary architecture with thyroid follicles.

Immunohistochemistry- the tumor cells were positive for TTF1.

\section{Management}

- Despite normal thyroid function, the multidisciplinary team decided that the patient will undergo prophylactic total thyroidectomy followed by the administration of $90 \mathrm{mCi}$ of 131। therapy.

- The WBS - small uptake in the area of the right ovary. Follow -up MRI at 5 months revealed no pathological sign.

- The patient is now under suppressive therapy with L4-thyroxin.

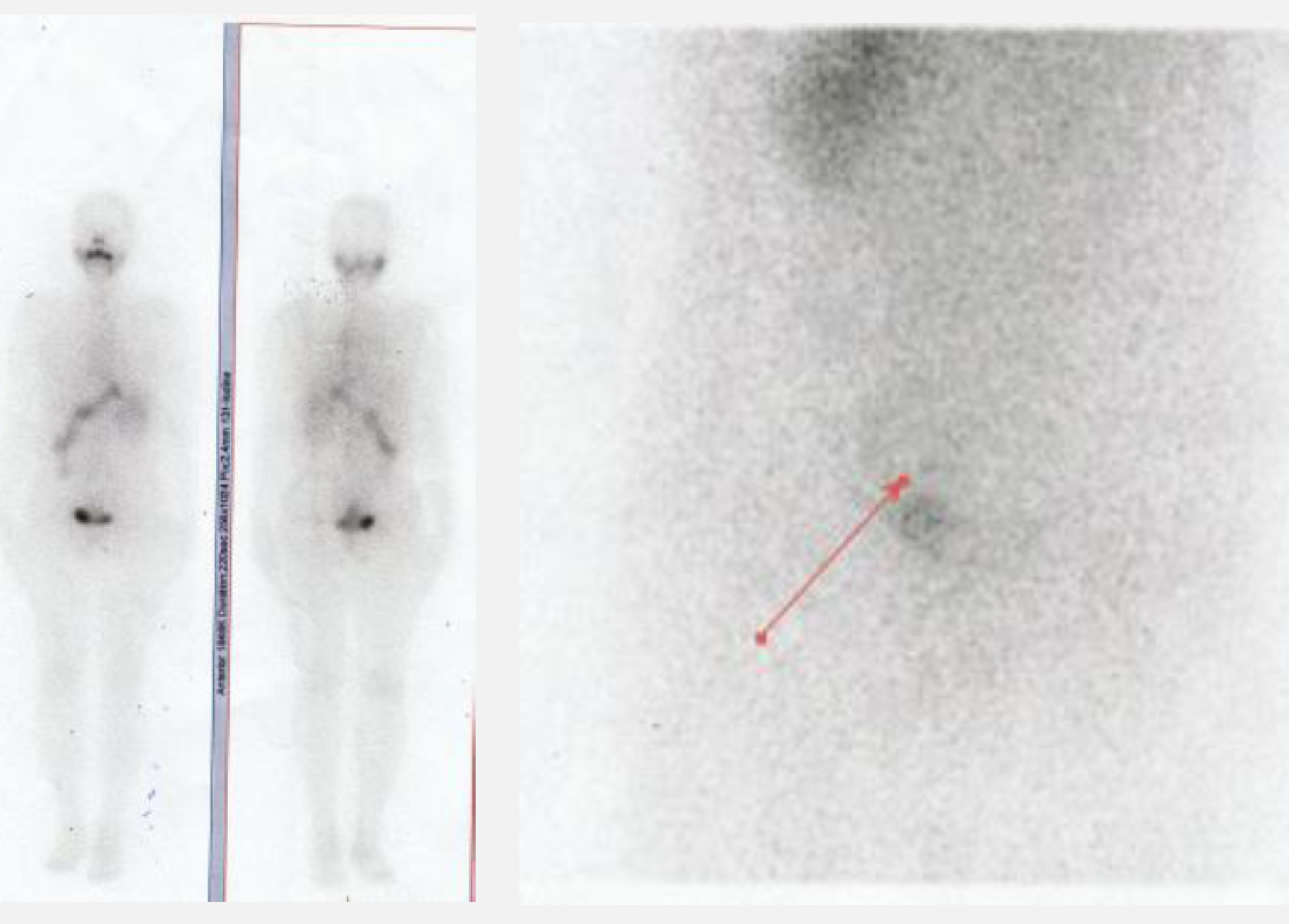

\begin{tabular}{|l|l|l|} 
& $\begin{array}{l}\text { September } \\
2014\end{array}$ & \multicolumn{1}{c|}{$\begin{array}{c}\text { October } \\
2015\end{array}$} \\
\hline Parameter/References & Pre-op & Post-op \\
\hline TSH ( 0.4-4 U/ml) & $1.21 \mathrm{ulU} / \mathrm{ml}$ & $93 \mathrm{uUl} / \mathrm{ml}$ \\
\hline FT4 ( $0.89-1.76 \mathrm{ng} / \mathrm{dl})$ & $1.14 \mathrm{ng} / \mathrm{dl}$ & - \\
\hline $\boldsymbol{\beta}$ hCG levels $(\mathbf{0 - 3 5} \mathrm{U} / \mathrm{ml})$ & $85 \mathrm{U} / \mathrm{ml}$ & 0 \\
\hline Thyroglobulin $(<0.04 \mathrm{ng} / \mathrm{ml})$ & - & \\
\hline & & $<0.04 \mathrm{ng} / \mathrm{ml}$ \\
\hline
\end{tabular}

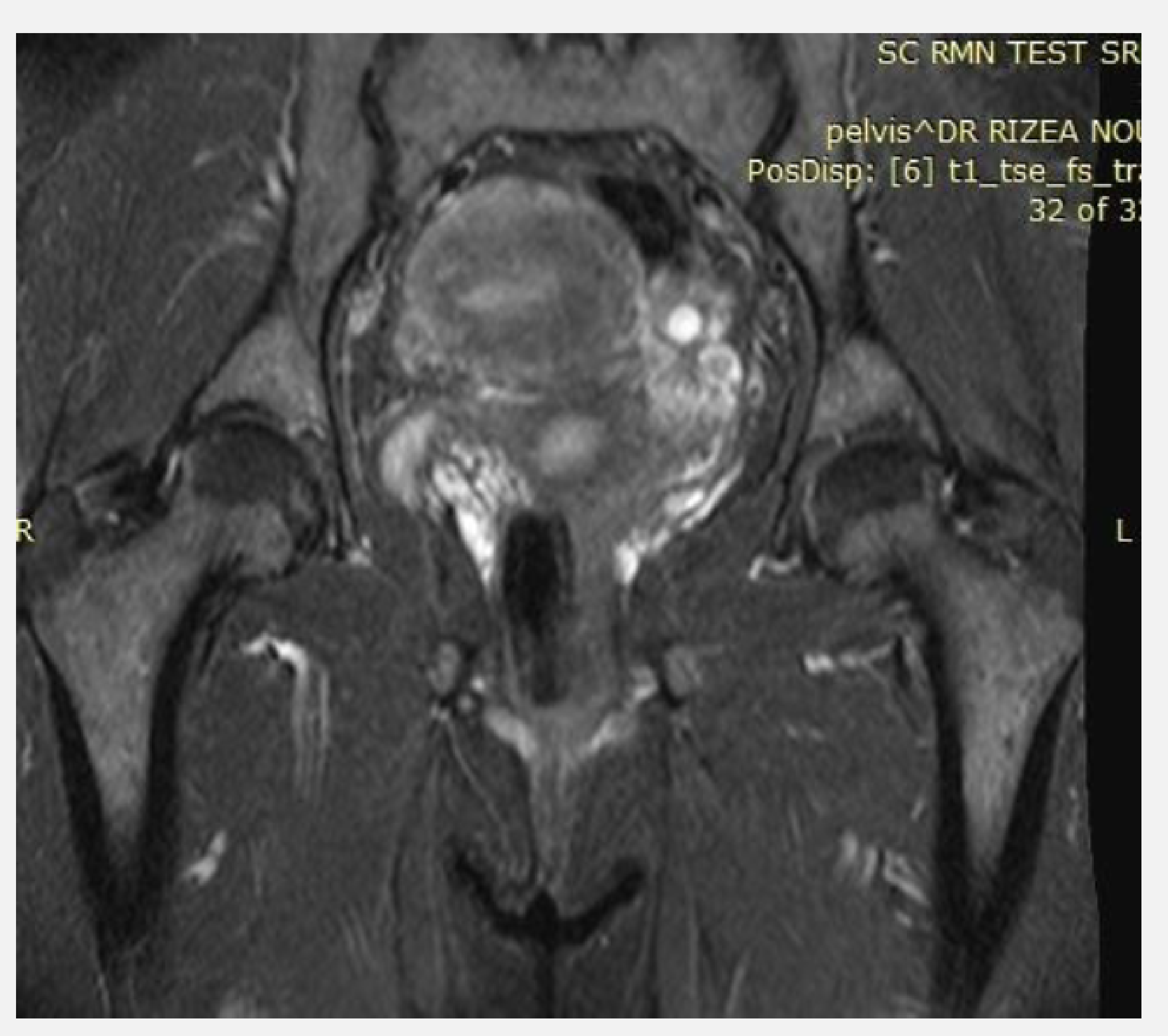

\section{Discussions}

- Reviewing the literature we came across conflicting data. Some authors have advocated the management of malignancy in struma ovarii as any other germ cell tumor while others have proposed that it should be treated like its thyroid counterpart. The latter is the favored approach in the recent literature.

- The prognosis of thyroid-type carcinoma arising in struma ovarii is difficult to estimate due to its rarity and the absence of consensus in treatment. At this time, the management it's based only on case reports and small cases series review.

- We consider attentive long-term follow-up can bring valuable data for the case management.

\section{References:}

Selvaggi F, Risio D,Waku M, et al. Struma ovarii with follicular thyroid-type carcinoma and neuroendocrine component: case report. World Journal of Surgical Oncology. 20I2;10:93. doi:I0.I I86/I477-78/9-10-93. 